\title{
Processo de Identificação e Correção de Erros da Plataforma OBAMA
}

\author{
Vitor Henrique Coelho Bezerra, Gildo Cordeiro Duarte, Jason Willyan Castro do \\ Nascimento, Moisés Oliveira Catônio de Araújo, Dennys Leite Maia \\ 1 Instituto Metrópole Digital - Universidade Federal do Rio Grande do Norte (UFRN) \\ Av. Sen. Salgado Filho, 3000 - Lagoa Nova, CEP: 59.078-970 - Natal - RN - Brasil \\ \{vitorhenrique908, gildo.duartec, \\ moises.catonio\} egmail.com, dennys@imd.ufrn.br, JasonWillyan@hotmail.com
}

\begin{abstract}
This article describes the steps of the process of identifying, analyzing and correcting errors found as well as tests performed on a collaborative platform, citing the importance of the error testing and correction process for the development of educational software, the methodologies adopted and the conclusions made. by the development team during a continuous period of testing and correction.

Resumo. Este artigo descreve as etapas do processo de identificação, análise e correção de erros encontrados assim como testes realizados em uma plataforma colaborativa, citando a importância do processo de teste $e$ correção dos erros para o desenvolvimento de um software educacional, as metodologias adotadas e conclusões feitas pela equipe de desenvolvimento durante um período contínuo de testes e correções.
\end{abstract}

\section{Introdução}

O processo de teste é parte importante para o ciclo de desenvolvimento de um software tanto por causa do seu objetivo: revelar falhas e identificar suas causas para que possam ser corrigidas pela equipe de desenvolvimento antes da entrega final; quanto para aumentar a confiança do software por meio da exposição destrutiva de seus defeitos [Dias-Neto 2007].

A identificação desses problemas ocorre por meio da averiguação do comportamento do sistema e a comparação disso com o que foi especificado. Os defeitos de um programa normalmente são introduzidos na transformação de informações entre as diferentes fases do ciclo de desenvolvimento dele. No processo de desenvolvimento de software, todos os defeitos são de origem humana e eles persistem apesar do uso dos melhores métodos de desenvolvimento, ferramentas e profissionais. $\mathrm{O}$ que torna a atividade de teste fundamental no processo de desenvolvimento de uma aplicação [Dias-Neto 2007].

Qualquer desenvolvedor de software deve prezar pela qualidade da interatividade entre usuário-final e o sistema computacional. Isto requer ainda mais atenção quando o produto é destinado para um público-alvo que, via de regra, possui pouca fluência tecnológica, como professores da Educação Básica [Toebe et al. 2018]. 
VIII Congresso Brasileiro de Informática na Educação (CBIE 2019)

Anais do XXV Workshop de Informática na Escola (WIE 2019)

Especificamente para aplicações com foco pedagógico, Oliveira, Amaral e Bartholo (2010), comparam cinco modelos de desenvolvimento colaborativo e ratificam a etapa de validação como fundamental e presente em todos os modelos e destacam sua importância para a manutenção da ferramenta.

A Plataforma OBAMA ${ }^{1}$ é um ambiente web desenvolvido que oferece a professores de Matemática da Educação Básica um repositório de Objetos de Aprendizagem (OA) classificados conforme critérios técnicos e pedagógicos [Oliveira et al. 2017], além da possibilidade de elaboração de planos de aulas que relacionam os OA presentes na plataforma [Batista et al. 2017]. Apesar da OBAMA já ser reconhecida na comunidade de Informática na Educação, inclusive com premiações [Oliveira et al. 2018], a busca por sua aprimoração com vistas à prática docente é constante entre os membros da equipe.

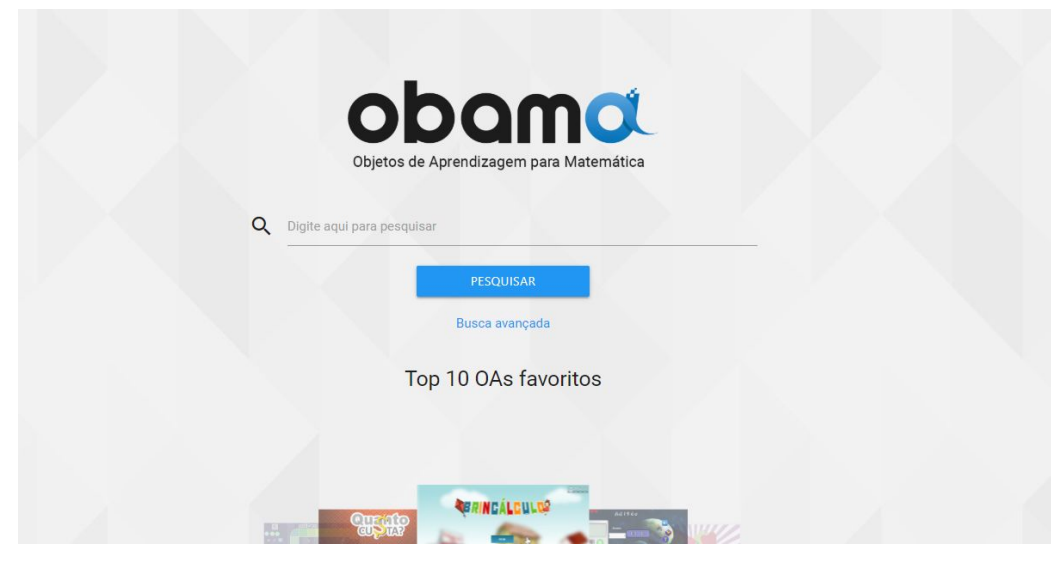

Figura 1. Página inicial da plataforma OBAMA

Neste sentido, a equipe da OBAMA possui dois Grupos de Trabalho (GT), quais sejam: (i) Pedagógico; composto por Doutores em Educação, mestres e mestrandos em inovações em tecnologias educacionais, pedagogos e licenciados em Matemática, é encarregado pela oferta das formações como também atua em demandas de caráter mais pedagógico como, por exemplo, a classificação do nível de ensino dos OAs; e (ii) dos Desenvolvedores; formado por Mestre em Sistemas de Informação, bacharéis, graduandos e técnicos da área de Tecnologia da Informação (TI) que trabalham nas demandas técnicas e na manutenção do ambiente web.

Prezando pela qualidade da OBAMA, o GT do desenvolvimento atuou na identificação dos erros, nos testes na plataforma além de estar à frente das formações da plataforma com o público-alvo.

Este trabalho objetiva relatar o processo de identificação de falhas e erros da plataforma e como foram procedidas à correção. Este artigo se organiza em, além desta introdução, mais quatro seções: metodologia, em que apresentamos o procedimento dos passos da realização do trabalho realizado pelo GT dos desenvolvedores; os resultados e discussões do processo de identificação e correção dos problemas encontrados; e, por fim, as conclusões realizadas até aqui.

\footnotetext{
${ }^{1}$ Objetos de Aprendizagem para Matemática (OBAMA)
} 
VIII Congresso Brasileiro de Informática na Educação (CBIE 2019)

Anais do XXV Workshop de Informática na Escola (WIE 2019)

\section{Metodologia}

O processo para identificar os problemas e demandas da OBAMA ocorre por quatro formas diferentes, quais sejam: (i) formações de professores presenciais realizadas pela equipe, nelas os usuários finais se disponibilizam a utilizá-la e cada erro encontrado é relatado e registrado por um membro da equipe de desenvolvimento do sistema in loco; (ii) formulário disponível na OBAMA; no canto inferior do site há opção para suporte, onde os usuários informam e descrevem os problemas encontrados que são enviados para o e-mail da plataforma, registrados em uma planilha de demandas e, posteriormente, discutidos em reuniões da equipe; (iii) relatos feitos pela GT pedagógico, a qual disponibilizou-se a procurar e relatar erros da plataforma, esses os quais são informados nas reuniões como também em documentos que detalham testes e possíveis erros da plataforma; e (iv) relato de testes por partes dos desenvolvedores, alguns membros atuavam como testadores e registravam todo o processo assim como o erro em uma planilha. Como recorte para este trabalho, será descrito, sequencialmente, o processo de correção de dois problemas encontrados por meio de duas formas: um relatado pelo formulário da plataforma e outro proveniente das formações realizadas pela equipe da OBAMA.

Todos esses erros e demandas levantadas pelo processo encontram-se dispostos em uma planilha colaborativa disponível a todos os desenvolvedores da equipe e marcados por nível de complexidade de correção, em uma escala de fácil, médio, difícil. Em seguida, a partir de discussões em reuniões cada desenvolvedor assume a responsabilidade para a solução do problema, independentemente ou por atribuição de um desenvolvedor mais experiente. Essas atribuições levam em consideração os diferentes estágios de formação, experiência dos membros do GT dos desenvolvedores com as tecnologias da plataforma e a dificuldade a qual é analisada por um membro mais experiente do grupo.

Com a demanda em mãos, os desenvolvedores passam a trabalhar na resolução do problema, e relatam semanalmente o avanço e as dificuldades enfrentadas. Todo esse processo gera uma troca de opiniões sobre abordagens para um certo problema, ou até mesmo de diferentes tipos de implementação para um mesmo trecho de código com intuito de melhorar seu desempenho e consequentemente a eficácia de funcionalidades da plataforma, além de proporcionar ganhos em experiência colaborativa e trabalho em equipe.

Após que as demandas são feitas, o responsável assim como um outro programador da equipe, geralmente mais dedicado a parte de teste, realiza um conjunto de testes manuais sobre a plataforma, levando em consideração contexto organizacional e social do usuário, para que assim possa verificar se elas não apresentam um comportamento inesperado ou até mesmo não atende a especificação. Esses testes levam em consideração contexto organizacional e social do usuário. Depois, o que foi desenvolvido passa por todos os testes necessários localmente, uma pessoa da equipe do GT responsável pelo upload das mudanças nos servidores da plataforma inicialmente verifica se a demanda apresenta algum problema, se não, encaminha para um servidor dedicado de testes. Caso contrário retorna para o responsável.

Após a demanda ser encaminhada para o servidor de testes, todo o sistema é 
VIII Congresso Brasileiro de Informática na Educação (CBIE 2019)

Anais do XXV Workshop de Informática na Escola (WIE 2019)

testado e caso ele esteja estável, periodicamente, o desenvolvedor responsável pelas mudanças nos ambientes web faz as alterações no servidor de produção da plataforma.

\section{Resultados e discussões}

Pelo formulário, foi relatado que os autores não conseguiam visualizar seus coautores. Para esse problema, foi verificado por meio de testes na criação do plano de aula e no compartilhamento dele na plataforma de que havia uma facilidade para que os usuários não autores de um plano excluissem a autoria dele. Aliado a esse problema, foi identificado que havia uma inconsistência na permissão de exclusão dos planos de aula. Isso estava inviabilizando a edição do plano pelos usuários, propagando erros e causando uma inconsistência no sistema.

Após discussões e sugestões trocadas entre os membros do GT dos desenvolvedores da plataforma em suas reuniões de complexidade média foi corrigido por um membro mais experiente com a reformulação das permissões de edições, exclusões e compartilhamentos do plano.

Já na formação de professores, um dos usuários relatou a um dos desenvolvedores, um bug na formatação das palavras no Portable Document Format (PDF) do plano de aula produzido. Foi identificado que os planos de aulas não apresentavam uma formatação adequada, de forma que as palavras encontravam-se sobre outras, impedindo a compreensão do plano de aula.

Para solucionar o problema identificado com a complexidade fácil, um programador com menos experiência em desenvolvimento ficou encarregado de corrigir a demanda e analisou através de testes que dependendo da quantidade de texto para alguns campos informados na criação do plano de aula, a visualização do arquivo PDF ficava comprometido.

Para corrigir esse problema, o encarregado foi orientado por um programador e alterou o padrão das orientações de visualização dos textos de cada parte do modelo do arquivo de modo que ele se adequasse dinamicamente a quantidade de textos.

Esses e outros exemplos, antes de irem para o servidor da plataforma, foram novamente testados em um ambiente dedicado. Eles caracterizam parte da experiência dos membros da equipe de desenvolvimento na aquisição de informação, em campo, sobre a utilização da plataforma pelos usuários finais e toda essa experiência auxilia na formação de profissionais mais qualificados na área. Grande parte do material elencado é utilizado não só como base de discussão pela equipe de desenvolvimento mas como passo inicial para criação de testes, como por exemplo, a recriação de fluxos de erros que foram observados ao realizar determinadas ações. Dando ênfase a importância do feedback constante durante o desenvolvimento de uma ferramenta tão robusta quanto à OBAMA e a como os processos de discussão, em torno da mesma, convertem-se num aprendizado colaborativo potencializando habilidades dialogais e diagnósticas em cada indivíduo.

\section{Conclusões}


Ter uma equipe de desenvolvedores que discutem durante $\mathrm{o}$ processo de desenvolvimento de um software, seja pessoalmente ou virtualmente, é uma experiência bastante construtiva para a execução e compreensão do processo de identificação e correção de problemas de um sistema. O processo descrito auxilia bastante em todo o ciclo de desenvolvimento e manutenção da OBAMA.

No entanto ele ainda é pouco eficiente já que todos os testes são feitos manualmente e tende a ser comprometido já que dentro do grupo não existe uma prática de sistematização de testes além de uma documentação de requisitos pouco desenvolvida.

Com a experiência de lidar com o tratamento de informações obtidas mediante discussão com usuários da plataforma e entre desenvolvedores da mesma, pode-se notar o ganho na aprendizagem por parte dos atores desses processos. A aprendizagem é advinda principalmente do trabalho colaborativo e da adaptação durante o processo de compreensão sobre o contexto dos problemas e dos usuários, por exemplo, simplificando a explicação e funcionamento de determinadas funcionalidades e conceitos mais específicos ao meio profissional da informática, entre outras formas de adaptação dos sujeitos que compõem a equipe técnica da plataforma. Estes são os primeiros achados da experiência da equipe de desenvolvedores da OBAMA.

Como trabalho futuro é prevista a melhoria na descrição dos requisitos e a sistematização desses processo de correção de erros e demandas de melhorias em um formato de formação, para que seja possível preparar os colaboradores que venham a integrar a equipe futuramente.

\section{Referências}

Batista, S.; Brito, D.; Melo, E.; Oliveira, A.; Oliveira, N.; Maia, D. (2017). "Reconstrução de um Repositório de Objetos de Aprendizagem para Matemática". In: Anais do Ctrl+E 2017. Mamanguape, PB: CEUR-WS. v. 1877. p. 59-70.

Dias-Neto, A. C. (2007). "Introdução a Teste de Software". In: Engenharia de Software Magazine, $1^{\text {a }}$ edição, p. 54-59.

Oliveira, K.; Amaral, M.; Bartholo, V. "Uma Experiência para Definição de Storyboard em Metodologia de Desenvolvimento Colaborativo de Objetos de Aprendizagem". In: Ciências \& Cognição. v.15(1), p.19-32.

Oliveira, A.; Silva, A.; Costa, C.; Maia, D. (2017). "Levantamento e Catalogação de Objetos de Aprendizagem para Matemática para Atualização de um Repositório". In: Anais do Ctrl+E 2017. Mamanguape, PB: CEUR-WS. v. 1877. p. 47-58.

Oliveira, A.; Batista, S.; Oliveira, N.; Maia, D. "OBAMA: Uma Plataforma para Inovação e Colaboração na Prática Docente”. In: Anais do WCBIE 2018. Fortaleza: SBC. p.156-163.

Toebe, I.; Mallmann, E.; Bageti, S.; Pereira, A. "Fluência Tecnológico-Pedagógica na Formação Inicial de Professores Mediada por Tecnologias Educacionais em Rede". In: Anais do WCBIE 2018. Fortaleza: SBC. p.1138-1146. 